\title{
KEEPING SCORE \\ ONE SCORE LATER
}

Two Decades of the Simulation \& Games Journal

\author{
RICHARD D. DUKE \\ NICOLE K. KEMENY \\ University of Michigan
}

Simulation \& Games, an International Journal of Theory, Design, and Research (hereafter called the "Journal") is approaching a milestone: In March of 1990 it will begin its third decade of publication. The current editor, Cathy S. Greenblat, was named editor-designate in March of 1979 and will, with the March 1989 issue, conclude a decade of service to the profession. It seems appropriate to mark the occasion by extending, on behalf of the profession, hearty thanks for a job well done!

To commemorate the occasion, it seemed that it might be rewarding to review the contribution of the Journal to the profession and to reflect on the changing concerns of the contributors during the nearly two decades of its existence. This is easier said than done. Gamers are a diverse lot. Consequently, articles in the Journal cover a wide range of subject categories, and each article can easily trigger several "key words" that reflect its content; in other words, the articles resist narrow categorization. Naturally, this increases the difficulty of attempts at Journal content classification. A description of the methodology employed is provided later in this article.

Before reporting on the evolution of the content of the Journal, and in order to appreciate its contribution to the profession, it is necessary to gain some perspective on the evolution of the profession itself; hopefully this quick review will be helpful. 


\section{A BRIEF HISTORY OF THE PROFESSION}

Gaming, in its many forms, may reasonably be regarded as the world's second oldest profession. Chess, checkers, Go, and endless other forms of "serious" play date from antiquity; it is not appropriate to trace this evolution in detail here. Recent gaming history certainly dates from the advent of the eighteenth-century use of military games, particularly by the Germans; this use continues today in all major countries for both tactical and strategic military purposes. It should be noted that this branch of gaming is quite distinct from the rest of the discipline as it is treated in the Journal (less than one-half of $1 \%$ of the articles in this Journal over the past two decades have addressed military games). It should also be noted that military games stress highly quantitative simulation with an emphasis on prediction. While it is appropriate to acknowledge the impact of this branch of the family tree on our origins, the simulation and games dealt with in the Journal are clearly of a different genre.

The second wave of serious gaming evolved in the world of business in the form of training exercises that appeared in the post-World War II era; business gaming remains a hardy offshoot of the profession that has become increasingly serious and purposeful over the years. In addition to specially developed training exercises that are now indigenous to virtually all major companies, it is not uncommon to find carefully developed policy exercises (both games and simulations) employed as standard corporate strategic planning tools. In contrast to military games, business-related applications of gaming/simulation are very much a part of the Journal's content (approximately $15 \%$ of the articles; their frequency has increased over time). The greater part of this literature, however, is reported through ABSEL (Association of Business Simulation and Experiential Learning).

It is less clear where to attribute the third major wave, as several developments in the field occurred simultaneously. Certainly academics concerned with a variety of urban problems contributed heavily to new gaming/simulation materials developed in the sixties; these efforts, in turn, generated pressure for the creation of the Journal. Urban planners, sociologists, edu- 
cators, and political scientists were prominent during this period. During the decade of the sixties many professors were experimenting with both games and simulations. Much of the gaming effort was driven by the dramatic changes in society that created new opportunities for experimentation in education; federal funding, since then greatly reduced, nurtured many neophyte gamers during this period.

A separate but overlapping wave of development in the arena of gaming/simulation was prompted by the advent of computers. At first these machines were mysterious and available to a select few; as they became ubiquitous, they became a solution looking for a problem. This in turn bred a new field of social science simulation concerned with prediction for policy and/or decisionmaking purposes; this branch of the family tree has withered over the two ensuing decades. Efforts at predictive simulation are now rare in the people-oriented social sciences. In other fields (e.g., economics) prediction has become a specialized area with its own advocates and journals, and these efforts are more or less disassociated from gaming/simulation as reported in the Journal.

Parallel to the development of computer-driven social science simulations were computer-dependent games for a great variety of subject applications (such as law and medicine). Few of these games attempted to predict; most used the computer simply as a bookkeeping tool. The majority, at least in the early years, were painfully oversimplified; in the past five years these games have become very sophisticated. They are certain to become the newest wave of simulation/games as the next (NExt) ${ }^{1}$ generation of computer and video technologies come into the price range of the average gamer.

Also emergent during this period was the quest for academic respectability for gaming/simulation activities; this has taken several decades. Many universities began to offer courses that employed and/or taught gaming/simulation starting in the midsixties. At the University of Michigan, this was the direct result of the pioneering work of Fred Goodman, Layman Allan, and Al Feldt, whose "Monday Night Games Club," begun in the early sixties (and continuing today), laid the groundwork for the subsequent formal academic offerings at the university. This 
culminated, in the fall of 1985 , with the institution of a formal certificate program in gaming/simulation through the Rackham Graduate School of the University of Michigan. A new era had begun for the profession.

The 1990s promise still another wave of gaming/simulation activity driven by the dual needs of increasing complexity and information availability, and the urgent need to establish communication in complex environments. The financial support of the federal government has largely evaporated; however, the private sector has now begun to support serious gaming efforts in earnest. It is now commonplace for various organizations to offer Requests for Proposals that involve gaming/simulation design and/or applications. In addition, corporate sponsorship is wellestablished and plainly on the rise for gaming/simulations which support strategic planning efforts as well as management training.

\section{THE ROLE OF THE JOURNAL}

By the late sixties, two broad categories of academics were seeking an outlet for the publication of their activities: those from a variety of disciplines who were using games for various substantive purposes, and those who were increasingly interested in the phenomenon itself. In March 1970, Volume 1, Number 1 of Simulation \& Games, an International Journal of Theory, Design, and Research was published (by SAGE Publications, then of Beverly Hills, California). Perhaps the best way to transmit the perspective of the editors (Michael Inbar and Clarice S. Stoll) as they began is to quote from their first editorial, which introduced the Journal:

A decade ago, this journal would have been impossible-for all practical purposes the field of social simulation did not exist then. [They describe their goals.] Our aims: to establish a forum for scholarly communication on any aspects of theory, research and design bearing on the use or development of simulation. ... We will consider without disciplinary preference any paper that deals with social behavior in the broadest sense of the term. Machine, man, and man-machine simulations will be equally acceptable. 
[Note the absence of a reference to gaming; over the ensuing two decades, the emphasis, as measured by the content of the Journal, has shifted considerably; see Table 2].

In describing materials unusable for the Journal, the editors first indicate that "descriptions of simulations" will be limited to a brief listing; they also rule out two-person games, referring these articles to the established Journal of Conflict Resolution. This accounts for the absence from the Journal of these aspects of gaming/simulation. The Journal has been published on a regular quarterly basis for two decades (with one exception); it has certainly become THE forum for those with a serious interest in gaming/simulation.

\section{THE EVOLUTION OF THE JOURNAL}

What has been the focus of the Journal? How has it evolved during these two decades? To answer this, an analysis of the content was undertaken. The research consisted of reviewing each article and/or book review that appeared in the Journal over an 18-year period to establish "key words" that reflected the content of each piece (please note that for the remainder of this article all the materials reviewed are referred to as "articles"). In turn, these key words were subsequently grouped into 25 major subject categories, which are reported here. In most cases several key words were attributed to each article; therefore, the number of articles does not correspond to the number of key words reported here. These findings were recorded year by year and then aggregated into three periods of six years each; the results are reported later in this article. Obviously, this procedure was not high science; rather, it was a subjective, judgmental activity. The purpose of the resulting figures is to give a feeling of the major shifts that have occurred in the profession; those seeking a more serious content analysis may find these preliminary findings useful in structuring further research.

A summary of the results is presented in Table 1. A more revealing breakdown is provided in Tables 3 through 6 , which 
show the results of a historical analysis of Journal content grouped into four categories:

increasing topics-subjects that occurred with increasing frequency stable topics - topics that seemed to be consistent in their appearance decreasing topics - subjects that appeared with diminishing frequency variable topics-topics whose frequency varied over time

The subjects assigned to each of the above categories are the result of a personal interpretation both in the original determination of the appropriate key words as well as in the analysis of the numbers. Readers are invited to recombine the numbers as they wish. The numbers in the tables refer to the number of times a key word was identified for the stated period, as follows:

Column I = 1970 through 1975

Column II = 1976 through 1981

Column III $=1982$ through 1987

Column IV = 18-year period

Table 1 identifies the 25 primary topics in descending order according to their frequency of appearance in the Journal for the three periods, and for the entire 18-year survey period. ${ }^{2}$ Table 1 indicates that the volume of topic appearances has been fairly consistent, averaging $352 \mathrm{key}$ words being found each period by the review process. The table seems to suggest that Education and Simulation have served as the backbone of the Journal (the two combined account for a very consistent average key word count $-87,86$, and 83 for the three periods reported); however, Table 2, which gathers the various aspects of Gaming together, indicates that Gaming-related articles have been the main focus of the Journal. Key word tallies for Gaming-related articles (68, 68 , and 50 for the three periods, totaling 186) exceeded the second-place category, Education, by almost $40 \%$.

At this point it is essential that the "key words" themselves, or at least their use in the analysis, be defined. It seems most useful to do so in conjunction with each word's appearance in a table. 
TABLE 1

Key Word Tally, Grand Total

\begin{tabular}{|c|c|c|c|c|}
\hline SUBJECT & I & II & III & IV \\
\hline 1. Education/Learning & 35 & 54 & 44 & 133 \\
\hline 2. Simulation/Quantification & 52 & 32 & 39 & 123 \\
\hline 3. Computer \& Data Systems & 25 & 15 & 38 & 78 \\
\hline 4. Social Science & 39 & 19 & 10 & 68 \\
\hline 5. Research on Gaming/Simulation & 17 & 27 & 18 & 62 \\
\hline 6. Psychology & 13 & 34 & 12 & 59 \\
\hline 7. Business & 9 & 20 & 23 & 52 \\
\hline 8. Gaming/Sim. Theory \& Method & 23 & 22 & 16 & 61 \\
\hline 9. Management \& Administration & 9 & 14 & 25 & 48 \\
\hline 10. Political Science & 17 & 19 & 11 & 47 \\
\hline 11. Behavioral Sciences & 15 & 13 & 13 & 41 \\
\hline 12. Research Using Gaming/Sim. & 15 & 10 & 10 & 35 \\
\hline 13. Urban/Regional Studies & 15 & 10 & 8 & 33 \\
\hline 14. Decision Making & 11 & 8 & 10 & 29 \\
\hline 15. Gaming/Simulation; General & 13 & 9 & 6 & 28 \\
\hline 16. Intemational & 4 & 6 & 12 & 22 \\
\hline 17. Communication & 7 & 7 & 6 & 20 \\
\hline 18. Economics & 10 & 3 & 5 & 18 \\
\hline 19. Organizational Theory & 4 & 1 & 12 & 17 \\
\hline 20. Human Resources & 4 & 9 & 4 & 17 \\
\hline 21. Systems Analysis & 13 & 0 & 0 & 13 \\
\hline 22. Environment & 5 & 3 & 5 & 13 \\
\hline 23. Planning & 5 & 4 & 4 & 13 \\
\hline 24. Training & 2 & 2 & 8 & 12 \\
\hline \multirow[t]{2}{*}{ 25. Negotiation } & 2 & 2 & 6 & 10 \\
\hline & 364 & 343 & 345 & 1,052 \\
\hline
\end{tabular}


TABLE 2

Key Word Tally, Game/Simulation Related

\begin{tabular}{l|c|c|c|c|}
\hline \hline SUBJECT & I & II & III & IV \\
\hline 5. Research on Gaming/Simulation & 17 & 27 & 18 & 62 \\
8. Gaming/Sim. Theory \& Method & 23 & 22 & 16 & 61 \\
12. Research Using Gaming/Sim. & 15 & 10 & 10 & 35 \\
15. Gaming/Simulation; General & 13 & 9 & 6 & 28 \\
& & & & \\
\hline
\end{tabular}

NOTE: These subjects are described as they appear in later tables.

For Tables 3 through 6, all subject headings introduced will be defined in explanatory text within the article.

\section{TOPICS ON THE INCREASE IN THE JOURNAL}

The six subject areas displayed in Table 3 are best interpreted as emergent categories of Journal content. A brief explanation of each subject follows.

\section{BUSINESS (\#7)}

Both business and finance are contained under this heading; it is a broad category that usually applies to classroom game/simulation used in academic business programs. Articles that deal with specific business exercises are included under this heading, as well as general topics such as research on academic business games, evaluations of their educational value or realism, design considerations, and so forth.

\section{MANAGEMENT AND ADMINISTRATION (\#10)}

Management is a topic that ranges from the very general and theoretical to the highly specific and applied. Management 
TABLE 3

Key Word Tally, Increasing Topics

\begin{tabular}{l|r|r|r|r|}
\hline SUBJECT & I & II & III & IV \\
\hline 7. Business & 9 & 20 & 23 & 52 \\
9. Management \& Administration & 9 & 14 & 25 & 48 \\
16. Intemational & 4 & 6 & 12 & 22 \\
19. Organizational Theory & 4 & 1 & 12 & 17 \\
24. Training & 2 & 2 & 8 & 12 \\
25. Negotiation & 2 & 2 & 6 & 10 \\
& & & & \\
\hline & 30 & 45 & 86 & 161 \\
\hline
\end{tabular}

encompasses more than just the corporate world; resource management issues, both general and specific, are fairly prevalent in the literature. Specific applications were most often found in administrative or natural resource settings. Administration deals more specifically with institutional environments other than the corporate, and may overlap with the "Training," "Organizational Theory," and "Decision-Making" categories.

\section{INTERNATIONAL (\#16)}

This category captures all foreign contributions to the Journal, most of which originated in Europe. Quite a bit of research, mainly in the social sciences and in the area of mathematical simulations, has been conducted in the Netherlands and in West and East Germany. International Trade was perhaps the most common subcategory addressed.

\section{ORGANIZATIONAL THEORY (\#19)}

Articles placed in this class were typically theoretical and addressed institutional behavior and structure. They were often 
quantitative in nature; problem solving was also a common theme.

\section{TRAINING (\#24)}

Training is a distinctly different category from "Education/ Learning" in that its purpose is to teach specific new behaviors to professionals in the field. Hospital staff and administrators or corporate branch managers (rather than student groups) are typical participants in such exercises. This is presently an area of high demand; the availability of corporate funding will probably drive emergent gamers to present more articles (and products) reflecting this subject matter.

\section{NEGOTIATION (\#25)}

The demand for gaming exercises in the area of negotiation, similar to that in the area of training, is increasing rapidly and can be expected to continue doing so. This is due, in part, to the existence of a significant center devoted exclusively to negotiation at Harvard University. This topic has applications across a variety of subject areas, but is treated as the primary object of study in many Journal articles. The subject's popularity, however, has not been reflected in the contents of the Journal to date.

\section{TOPICS THAT APPEAR TO BE REMAINING STABLE}

These eight topics have been more or less consistent in their appearance in the Journal over the three periods (their combined average for the three periods being 115). It is no surprise that articles dealing with education are the dominant group; the majority of the contributors to the Journal appear to be from the academic community and are concerned with the efficacy of gaming techniques for teaching. Second most dominant of the "stable" category are the gaming-related topics (categories 8 and 12 ), which account for 38,32 , and 26 key word appearances in the three periods, totaling 96 citations. 
TABLE 4

Key Word Tally, Stable Topics

\begin{tabular}{l|r|r|r|r|}
\hline SUBJECT & I & II & III & IV \\
\hline 1. Education/Learning & 35 & 54 & 44 & 133 \\
8. Gaming/Sim. Theory \& Method & 23 & 22 & 16 & 61 \\
11. Behavioral Sciences & 15 & 13 & 13 & 41 \\
12. Research Using Gaming/Sim. & 15 & 10 & 10 & 35 \\
14. Decision Making & 11 & 8 & 10 & 29 \\
17. Communications & 7 & 7 & 6 & 20 \\
22. Environment & 5 & 3 & 5 & 13 \\
23. Planning & 5 & 4 & 4 & 13 \\
& 116 & 121 & 108 & 345 \\
\hline
\end{tabular}

EDUCATION/LEARNING (\#1)

This is a huge subject area encompassing teaching, learning, and the field of education. It is distinguished from Training (\#24) in that this area is concerned with creating an environment for learning and experimentation, rather than simply conveying information in an efficient manner. It is probably the discipline most closely associated with gaming/simulation techniques, and appears with the greatest frequency of any subject area in the Journal (although the four Gaming topics combined constitute a greater number of key words; see Table 2). Numerous classroom applications of gaming/simulation exist at all levels of the educational system. There are also many studies of the value of these techniques as teaching tools not only for full-time students, but for every imaginable group requiring continuing education. The combination of gaming and teaching has been researched, reviewed, and evaluated by academics and professionals in 
various fields, especially those of education, psychology, and sociology.

\section{GAMING/SIMULATION THEORY AND METHOD (\#8)}

"Theory" explores the phenomenon of gaming/simulation; articles concerned with theory appear with surprisingly low frequency. Apparently the theory of gaming/simulation is perceived to be of little interest to many of those involved in the field. The writings in this area are attributable to a handful of authors and orientations. The heading "Method" describes articles that address the "how to" (design, construction) of gaming/simulation. Although this is a recurring topic in the Journal, it is not nearly so well represented as one might expect, especially considering its overlap with research conducted on gaming/simulation (\#5 on the list, see Table 2).

\section{RESEARCH USING GAMING/SIMULATION (\#11)}

Many researchers start with the assumption that gaming/simulation is a legitimate research technique. Many disciplines use this technique in both a quantitative and a qualitative manner. The most frequent applications are in the observation and modification of psychosocial behavior.

\section{BEHAVIORAL SCIENCE (\#12)}

These articles are concerned with human behavior; gaming/simulation has been used as a technique for observing and/or modifying human behavior in a variety of situations. This category overlaps a great deal with "Psychology," "Sociology," and "Research Using Gaming/Simulation," but constitutes a significant body of literature meriting a heading of its own. Research has been done regarding behavior both during, and as a result of, gaming/simulation. Various aspects of role-playing also come under this heading. 


\section{DECISION MAKING (\#14)}

Many of the articles have addressed the process of human decision making. Although the literature in this area can be abstract and theoretical, it often applies to specific administrative and business or management environments. In cases where the treatment is theoretical, it is usually also quantitative, and/or deals with the evaluation of models and the efficacy of specific gaming/simulation exercises.

\section{COMMUNICATION (\#17)}

Efficient message exchange is of vital importance in human interactions; there is in particular a need for discussion and analysis of systemic relationships in complex environments. Communication is one of the human skills most often associated with gaming; the enhancement of communication is a viable use of gaming/simulation exercises.

\section{ENVIRONMENT (\#22)}

The topics of natural resources, land use, and recreation fit under this heading. These do not occur with great frequency, but are a noticeable presence in the literature. Most common is the issue of resource allocation.

\section{PLANNING (\#23)}

Planning, as used here, is mainly of three types: resource, business, and strategic, and as such inevitably overlaps with various corresponding categories. Forecasting also falls under this heading, and represents (not surprisingly) the quantitative side of the planning question. This topic is an established one in the gaming/simulation literature; it is typically applied as a problem-solving technique. It is by no means as frequent in its occurrence in the literature as such firmly established fields as education and management. 
TABLE 5

Key Word Tally, Decreasing Topics

\begin{tabular}{l|c|c|c|c|}
\hline SUBJECT & I & II & III & IV \\
\hline 4. Social & 39 & 19 & 10 & 68 \\
13. Urban/Regional Studies & 15 & 10 & 8 & 33 \\
15. Gaming/Simulation & 13 & 9 & 6 & 28 \\
18. Economics & 10 & 3 & 5 & 18 \\
21. Systems Analysis & 13 & 0 & 0 & 13 \\
& & & & \\
\hline
\end{tabular}

\section{TOPICS THAT APPEAR TO BE DECREASING IN THE JOURNAL}

These five subject areas are on the wane in the Journal. Generally, a decline in the subject's popularity since the Journal's inception is the cause; in some cases, however, the appearance of new journals that have diverted articles is responsible.

\section{SOCIAL (\#4)}

A broad heading was needed to contain the considerable literature encompassing social science, society, socioeconomics, sociology, attitudes, and morals/values. A study of the gaming/ simulation literature makes clear the very strong links between social concerns and the field of gaming/simulation. It is a category that, in some cases, overarches other major ones such as those falling under the general heading of "Business" and "Behavior," even "Education," and definitely "Human Resources." As such, gaming/simulation's connection with social research and concerns seems to represent a fundamental relationship. 


\section{URBAN/REGIONAL STUDIES (\#13)}

This area encompasses such concepts as community development, planning, design, comprehensive planning, housing, and transportation, which appear fairly frequently in the gaming/simulation literature. Urban, regional, and comprehensive planning appeared with the greatest frequency, with community concerns close behind. Transportation, as expected, tended to be treated in a quantitative fashion. Urban/regional studies is a well-established field with accepted links to gaming/simulation, but its representation has been far less than that of the primary fields of education, simulation (mathematics), social science, psychology, business, and management.

\section{GAMING/SIMULATION; GENERAL (\#15)}

This is a general category encompassing writings that deal with such overarching topics in the field of gaming/simulation as reflections on the use of the technique, philosophy of gaming/ simulation, and miscellaneous observations on the subject.

\section{ECONOMICS (\#18)}

The economics of a specific issue or organizational setting are addressed, as well as Keynesian economics in the context of mathematical models. There is also a great deal of overlap with Education (instruction in Economics).

\section{SYSTEMS ANALYSIS (\#21)}

Many types of systems were analyzed in articles placed under this heading. These were divided approximately evenly between the qualitative (studies of social or organizational systems) and the quantitative (systems modeling or simulation).

\section{TOPICS THAT HAVE VARIED IN THE JOURNAL}

Six topics have not been consistently evident in the Journal. This appears to result from changing editorial policy (6 and 10), 
TABLE 6

Key Word Tally, Variable Topics

\begin{tabular}{l|r|r|r|r|}
\hline SUBJECT & I & II & III & IV \\
\hline 2. Simulation/Quantification & 52 & 32 & 39 & 123 \\
3. Computer \& Data Systems & 25 & 15 & 38 & 78 \\
5. Research on Gaming/Simulation & 17 & 27 & 18 & 62 \\
6. Psychology & 13 & 34 & 12 & 59 \\
10. Political Science & 17 & 19 & 11 & 47 \\
20. Human Resources & 4 & 9 & 4 & 17 \\
& & & & \\
\hline & 128 & 136 & 122 & 386 \\
\hline
\end{tabular}

changing technologies ( 2 and 3 ), and a shifting of interest among contributors to the Journal ( 5 and 20 ).

\section{SIMULATION/QUANTIFICATION (\#2)}

This category encompasses articles dealing with mathematical models and quantitative simulations. Overall, it appears with the second greatest frequency of any topic. Most commonly, such articles discuss mathematical game theory, education, or the construction and evaluation of models. There is considerable cross-over with the business literature, which relies heavily on quantitative simulation.

\section{COMPUTER AND DATA SYSTEMS (\#3)}

The integration of computers into gaming/simulation has been widespread since the technique's inception, and is not limited to any particular discipline. Computers are very commonly used in business simulations, not surprisingly in transportation simulations, and in many educational exercises. The literature dealing 
with computer simulations and games is plentiful, and spans everything from the purely quantitative models, such as are used in traffic studies, to nonquantitative activities, such as may be used to teach social behavior to juvenile delinquents. "Data Systems" encompasses a number of subheadings, including Information, Data, and Data Processing. The subheading "Information" is clearly rather broad, and sometimes overlaps with other categories such as "Education/Learning" and "Organizational Theory."

\section{RESEARCH ON GAMING/SIMULATION (\#5)}

This represents the predominant endeavor linking gaming/simulation techniques with research. Such research is most often concerned with behavior as a result of gaming activities or evaluates the effectiveness of various design techniques or methodologies.

\section{PSYCHOLOGY (\#6)}

"Psychology" obviously overlaps a good deal with "Behavior," "Human Resources," and "Social Science," as articles in these categories tend to be rather broad in their coverage of issues, that is, not easily pigeon-holed into single topics. This is a richly represented field in the Journal, although not nearly as ubiquitous as its more general counterpart, the "Social Science" category.

\section{POLITICAL SCIENCE (\#9)}

This category addresses articles that focus on the field of political science, but also includes governmental and other policies. There is also quite a bit of overlap with "Education" (instruction in political science) and "International."

\section{HUMAN RESOURCES (\#20)}

This is a category that addresses specific groups of people, including blacks, children, adolescents, women, and men. It is 
obviously related to psychology and sociology (and to a number of other fields, such as education and law), but is so categorized due to the emphasis on the special characteristics or problems of the particular group as differentiated from the rest of society.

\section{CONCLUSION}

Table 1 lists the subject categories found in the Journal that we have judged to be the most significant and displays them in descending order of frequency. This provides a broad view of the results of the key word search and each topic's contribution to Journal content over the years. Table 2 groups the four aspects of gaming, revealing a composite score that surpasses any other single category covered in the Journal. Table 3 makes clear the prominence and rise of the business-related subjects in the Journal, which experience tells us is a true reflection of current developments in the gaming/simulation profession. Table 4 affirms the continuing relationship between gaming/simulation and disciplines such as education and communications, which have traditionally been its closest associates. Table 5 shows the changing orientations of the Journal and the profession, and reflects the tendency for new fields (e.g., systems analysis) to expand into full-fledged disciplines with independent academic programs and publishing outlets. Table 6 demonstrates the Journal's tendency to reflect the fluctuations of societal and academic interest in particular topics and technologies.

The Journal has been the primary mechanism of communication among those interested in the gaming world. It has been successful and has met the hopes of the original editors: "To establish a forum for scholarly communication on any aspect of theory, research and design ... which deals with social behavior in the broadest sense of the term." The results are a bit eclectic, to be sure; but in the opinion of these authors, their original objectives were valid and have been successfully fulfilled.

In the coming decade, it is reasonable to expect a shift in the content of the Journal from intellectually driven to more marketdriven activities; it is also reasonable to expect the articles 
emerging during the next decade to be heavily influenced by new technologies. This is so for two reasons: First, gamers have a much better understanding of their trade than they had 20 years ago (and as a consequence they can create more useful products more quickly); second, the demand for improved comprehension of systemic relationships (gaming) and the specific detail required for decision-making activities (technology) are both increasing (consequently there will be increased pressures for gamers to become more market driven).

Any speculation about the future of the profession is hazardous; nonetheless, it might prove fruitful to raise some of the issues that could become problematic in the coming decade. Perhaps editorial policy should encourage (through special issues devoted to the topics, etc.) attention to concerns such as:

- the impact of the next generation of technology on the profession in an increasingly market driven arena (e.g., corporate planning and training)

-a broadening of the spectrum of subject areas to which gaming/ simulation is applied

- the emergence of a trend linking gaming to expert systems developmental activities

- the need for more careful design procedures and the delineation of professional standards

- the need for more emphasis on the critical evaluation of gaming exercises

- a careful review of the various ethical issues raised by the use of games in academic and business environments

- the significance of the trend towards area-specific journals (such as business and conflict resolution).

\section{NOTES}

1. NExt is the most recent generation of the personal computer. It was introduced by Steve Jobs in 1988.

2. Topics making one-time-only or very rare appearances in the Journal are architecture and design, legal, operational, logistics, and military; these are not reported in this article. 